\title{
Correction to: China English in World Englishes
}

\section{Correction to:}

D. He, China English in World Englishes, Asia in Transition 12, https://doi.org/10.1007/978-981-15-8187-8

The original version of the book was inadvertently published with 12 as the book volume number, which has now been updated to 10 . The book has been updated with the change.

The updated version of the book can be found at https://doi.org/10.1007/978-981-15-8187-8 